\title{
Application of the Three-Dimensional Environmental Fluid Dynamics Code Model in Manwan Reservoir
}

\author{
L. $\mathrm{Li}^{1 *}$, J. Wu ${ }^{1 *}, \mathrm{X}$. Wang ${ }^{1}, \mathrm{H}$. L. Zhou ${ }^{1}$, B. Fang ${ }^{1}$ \\ ${ }^{1}$ State Key Laboratory of Water Resources and Hydropower Engineering Science, Wuhan University. \\ Wuhan 430072, China \\ Email: jwu199053@sohu.com
}

\begin{abstract}
The water temperature prediction has been one of the important contents of the environmental impact assessment on the hydropower projects. The paper summarized advances in water temperature research for reservoir in China and abroad and studied the structure of the Environmental Fluid Dynamics Code (EFDC) model. The measured data for model calibration include hydrological, atmospheric and water temperature data of Manwan Reservoir in Yunnan province for 29 days, from February 1 to February 29, 2004. The calibrated result shows that the average of absolute mean error of the three vertical lines in front of dam is $-0.15^{\circ}$ and the average of relative error is approximately $2.0 \%$. The model was validated from February 2003 to January 2004. The absolute mean error is $-0.36^{\circ}$. The EFDC model simulations exhibit the same trends as the observations.
\end{abstract}
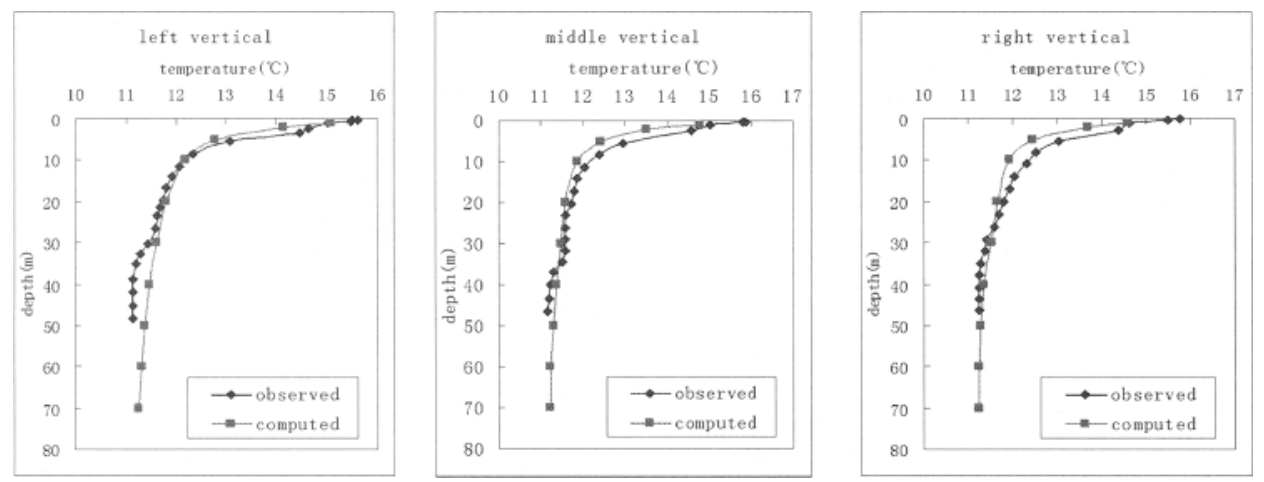

Figure: Model simulated and observed water temperatures at the left, middle, right vertical lines in front of dam site on February $18^{\text {th }}, 2004$

\section{REFERENCES}

1. Hamrick J. M. A three-dimensional environmental fluid dynamics computer code: theoretical and computational aspects. Special Report 317 in Applied Marine Science and Ocean Engineering. 1992. The College of William and Mary, Virginia Institute of Marine Science. $63 \mathrm{pp}$

2. Hamrick J. M, Mills Wm. Three-dimensional hydrodynamic and reactive transport modeling of power plant impacts on surface water systems. Tetra Tech, Inc.3746 Diablo Blvd., Suite 300, Lafayette, CA 94549

3. Deng Y. Study on the water temperature prediction model for the huge and deep reservoir. Chengdu: Sichuan University, 2003. (in Chinese) 